\title{
Application of seismic sedimentology to the western slope of northern Songliao basin
}

\author{
Ji Xianwei*1 \\ ${ }^{1}$ Exploration and Development Research Institute of Daqing Oilfield Company Ltd., PetroChina, Daqing 163712, Heilongjiang, China
}

\begin{abstract}
During the sedimentary period of Saertu reservoir on the western slope of the northern Songliao basin, delta front and shore-shallow lake subfacies are mainly developed, which have the characteristics of few sandstone layers and thin single layer thickness. The lithology of thin layer or thin interlayer can not be distinguished clearly by seismic response on conventional seismic section, and it is difficult to identify them. Geophysical response characteristics of channel sand bodies are defined by well-seismic combination. Under the guidance of seismic sedimentology, the qualitative and quantitative prediction of channel sand bodies is carried out by using $90^{\circ}$-phase conversion, stratal slicing and waveform indication inversion techniques. The results show that the seismic reflection axis is symmetrical with respect to the top and bottom surface of sandstone, and the channel sand body has obvious characteristics and completely corresponds to wave peak reflection. The channel bodies of S1 and S23 reservoir formation are separated respectively into two stages by using the amplitude attributes of stratal slices, and the coincidence rate of reservoir prediction to wells is $78 \% \sim 84 \%$, with an average of $79.7 \%$. The waveform indicator inversion technique is used to predict the channel sand body thickness of the four stages, and the error of sand body thickness to well is $0 \sim 1.6 \mathrm{~m}$, with an average of $0.32 \mathrm{~m}$.
\end{abstract}

\section{Introduction}

The western slope is one of the potential favorable areas for oil and gas exploration in the north of Songliao basin $^{[1,2]}$. In recent years, three-dimensional seismic exploration has been carried out in five blocks with a full coverage area of more than $1 \times 10^{3} \mathrm{~km}^{2}$ on the western slope. Predecessors used $3 \mathrm{~d}$ seismic amplitude attribute to predict the channel sand body on the west slope ${ }^{[3-5]}$. But according to the drilling data, seismic response to the distinction between the lithology is not clear, the same seismic reflection amplitude axis reflected the different lithology ${ }^{[3]}$, analysis the reason for the conventional seismic processing results is zero phase of seismic data, sand body with no direct corresponding relationship between seismic event, the polarity and amplitude can neither well lithology, nor lithofacies credible reference point of the position and form, so the standard of zero phase seismic data is not suitable for thin layer lithology interpretation ${ }^{[6,7]}$. In recent years, seismodeology has been widely applied in oil and gas exploration $^{[8-16]}$, playing an important role in characterizing thin sand bodies, characterizing reservoirs and predicting lithologic traps ${ }^{[10]}$. Based on the theory of seismic sedimentology, this paper explores the correspondence between the synfacies axis of seismic reflection and the lithology by using the threedimensional seismic data processed by the strip, so as to develop the qualitative and quantitative prediction of channel sand bodies.

\footnotetext{
* Corresponding author: jackdqpi@163.com
}

\section{Geological survey of the study area}

The western slope of the northern Songliao Basin is structurally composed of three secondary tectonic units, the western overlap belt, the Taikang uplift belt and the Fuyu tectonic belt. Since the Cretaceous period, it has been an easterly inclined monoclinal structure ${ }^{[17]}$. The overall structure is relatively simple and the fault does not develop ${ }^{[18]}$. The main target layer of the western slope is saertu oil formation, namely from the second and third sections of Yaojia Formation to the first section of the Nenjiang Formation, which is divided into S23, S1 and S0 oil formation from bottom to top, and the main oil-bearing formations are S23 and S1 oil formation. The sedimentary microfacies mainly developed in the delta front subfacies and shore-shallow lake subfacies ${ }^{[19-26]}$, and the sedimentary microfacies include subaqueous distributary channel, estuarine bar, sheet sand, distributary bay, shore-shallow lake sand bar and shoreshallow lake mud in the delta front. The sedimentary microfacies of oil-bearing sandstone are mainly subaqueous distributary channel, followed by sheet sand. Under the influence of the northern provenance, the sand body thickness of the Saertu oil formation gradually thinned from the S23 oil formation to the S0 oil formation during the deposition period. The sand body thickness of the S23 oil formation is generally $5 \sim 8 \mathrm{~m}$, and the sand body thickness of the S0 and S1 oil formation is generally $2 \sim 5 \mathrm{~m}^{[27]}$. The sandstone to 
formation thickness ratio of the S23 oil formation is generally $40 \% \sim 60 \%$, that of the $\mathrm{S} 1$ oil formation is generally $10 \% \sim 20 \%$, and that of the S0 oil formation is generally less than $10 \%$. The single sand layer thickness of Saertu oil formation is generally between $1 \mathrm{~m}$ and $2 \mathrm{~m}$. It is characterized by fewer sandstone layers and thinner single layer thickness, which is a typical "mud-coated sand" feature.

\section{3 geophysical response characteristics}

\subsection{Geophysical response characteristics of the SO oil formation}

There are differences in the geophysical response characteristics of channel sand bodies in different areas of the S0 oil formation on the western slope. The log response of channel sand body is characterized by low speed and low density, and the seismic response is characterized by weak amplitude reflection. The channel sand body shows the characteristics of "upper arch" in the same phase axis in the seismic profile. In the middle region, the channel sand body is mainly developed in the middle and upper part, and large sheet sandstone is developed all around. The logging response of the channel sand body is characterized by low speed and low density, the seismic response is characterized by weak amplitude reflection, and the channel sand body shows the "pull-down" feature of the same phase axis in the seismic profile. In the southern region, the channel sand body is mainly developed in the middle and mudstone is developed all around. The logging response of the channel sand body is characterized by high speed and high density. The seismic response is characterized by strong amplitude reflection. At the same time, the channel sand body of The S0 oil formation shows opposite geophysical characteristics to the surrounding sheet sand (or mudstone).

\subsection{Geophysical response characteristics of S1 and $\mathbf{S 2 3}$ oil formation}

The density of sandstones in the channel of S1 oil formation on the western slope is less than $2.1 \mathrm{~g} / \mathrm{cm}^{3}$, and the acoustic time difference is greater than $380 \mu \mathrm{s} / \mathrm{m}^{[28]}$. The logging response is characterized by low density and low speed, and the seismic response is characterized by weak amplitude reflection. The density of channel sandstone in the S23 oil formation is less than $2.15 \mathrm{~g} / \mathrm{cm}^{3}$, the acoustic time difference is greater than $360 \mu \mathrm{s} / \mathrm{m}$, the logging response is characterized by low density and low velocity, and the seismic response is characterized by weak amplitude reflection. At the same time, the channel sand bodies of the S1 and S23 oil formations have opposite geophysical response characteristics with the surrounding mat sand, the log response of the mat sand is characterized by high density and high speed, and the seismic response is characterized by strong amplitude reflection.

\section{Prediction of channel sand body based on seismic sedimentology}

Seismic sedimentology is a geological discipline based on modern sedimentology, sequence stratigraphy and geophysics, which uses $3 \mathrm{~d}$ seismic data and geological data to determine the macroscopic characteristics of stratigraphic rocks, the origin of sand bodies, the development and evolution of sedimentary systems, the quality of reservoirs and the distribution of oil and gas through the study of sequence stratigraphy, stratigraphic slices, seismic attribute analysis, core lithology and sedimentary facies ${ }^{[29]}$. The main research methods and technologies include 90-degree phase conversion technology, formation slicing and geophysical inversion, etc. ${ }^{[9]}$, among which 90-degree phase conversion, formation slicing and frequency division interpretation are the key technologies of seismodeology ${ }^{[30]}$. In this paper, based on the 90 degree phase transformation, the stratigraphic slicing technology is applied to the qualitative prediction of the channel sand body on the west slope, and then the waveform indication inversion (phase control) technology is applied to the quantitative prediction of the channel sand body.

\subsection{0 degree phase conversion}

The results of conventional seismic processing are usually zero-phase seismic data, and the peaks and troughs correspond to the stratigraphic interface rather than the lithologic interface, which makes it difficult to identify sand body types. By rotating the seismic phase by 90 degrees, the main valve of the reflected wave is brought to the center of the thin layer, and the seismic reflection is symmetrical to the sandstone layer rather than to the top-to-bottom interface of the stratum, so that the seismic response has a unique corresponding relation with lithology, and the seismic phase has lithologic and stratigraphic significance ${ }^{[6,7,30]}$. From the zero-phase seismic profile which obtained from conventional seismic processing of the western slope, the seismic reflection characteristics of the sand body are shown as partial trough and peak reflection (Figure 1a), and the seismic response is not the only corresponding relation with lithology. After converting the original seismic record into 90 degree phase using 90 degree phase conversion technology, the seismic reflection axis is symmetric with respect to the sandstone layer, rather than with respect to the top and bottom interface of the stratum (Figure 1b). The channel sand body has obvious characteristics, which completely correspond to the crest reflection.

\subsection{Formation section}

Common seismic attribute slicing methods include time slicing, slices along the layer and stratigraphic slicing ${ }^{[31,32]}$. Time slice is to slice and display the seismic data when traveling along a fixed earthquake, and the direction of the slice is perpendicular to the time axis. Slices along the layer is sliced along or parallel to the 


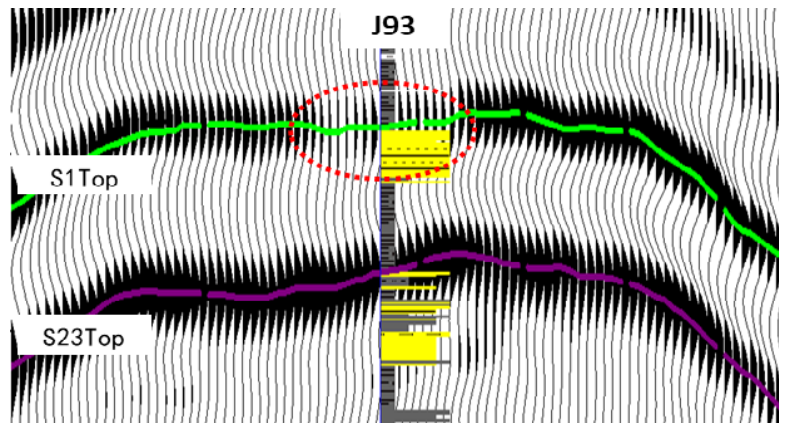

(a)seismic profiles before phase conversion

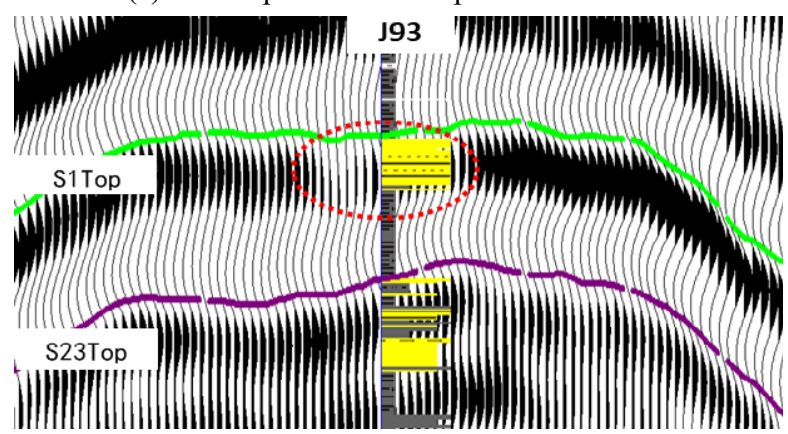

(b)seismic profiles after phase conversion

Figure 1. Comparison of seismic profiles before and after 90 degree phase conversion(Well J93)

seismic layer ${ }^{[33]}$. However, stratigraphic slicing take the isochronous sedimentary interface as the top and bottom to interpolate a series of layers in an equal proportion, and sections are generated one by one along these interpolated layers ${ }^{[30]}$. The $\mathrm{S} 1$ and $\mathrm{S} 23$ oil formation of West slope have the characteristics of sand bodies superimposed with each other. In order to separate the channel sand body, on the basis of 90degree phase conversion, six linear layers were inserted into the top and bottom of the S1 and S23 oil formation on the basis of stratigraphic slices to refine the channel period, and the amplitude properties along the layer were extracted (Figure 2). From the amplitude property diagram of the strata sections, the northwest is the lacustrine facies, and the lithology is the large set of mudstone and siltstone mudstone. The seismic property corresponds to the contiguous blue low value region. In the east is the delta facies, whose lithology is mainly siltstone, fine sandstone and argillaceous siltstone, and the seismic property corresponds to the high value region dominated by red, yellow and green. According to the distribution characteristics of stratigraphic section channel, sand bodies in two stages of each channel were identified for The S1 and S23 oil formations (Table 1). It is relatively simple to predict two-stage channel by using amplitude attribute without superposition of channel sand body in S0 oil formation.

\subsection{Waveform indication inversion}

Waveform indication inversion is a process of optimizing the combination of reflection coefficients under the guidance of seismic waveform characteristics(phase control). The theoretical basis of the algorithm is the structural data body distributed intensively in space, which reflects the spatial changes of the characteristics of underground deposition and lithologic association ${ }^{[34,35]}$. Waveform indicates inversion is the basic thought of in a framework of Bayes, on the basis of conventional post-stack seismic inversion, using seismic waveform similarity optimization related well samples, reference samples spatial distance and distribution characteristic

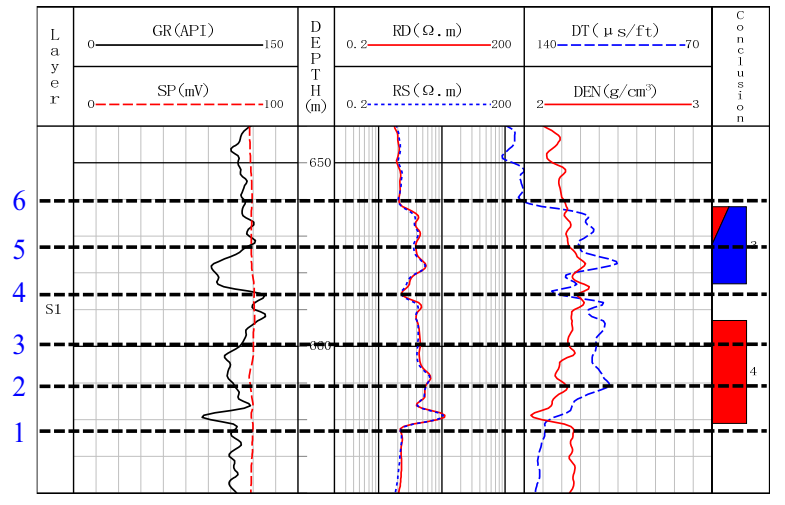

(a) Comprehensive log interpretation result chart of Well J67

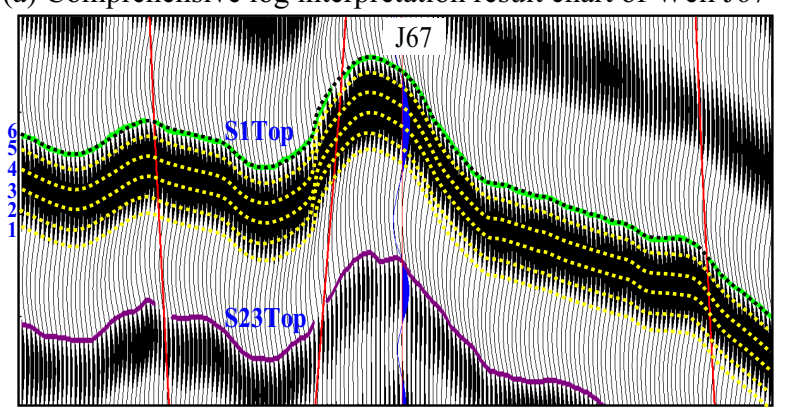

(b) Seismic profile of well J67

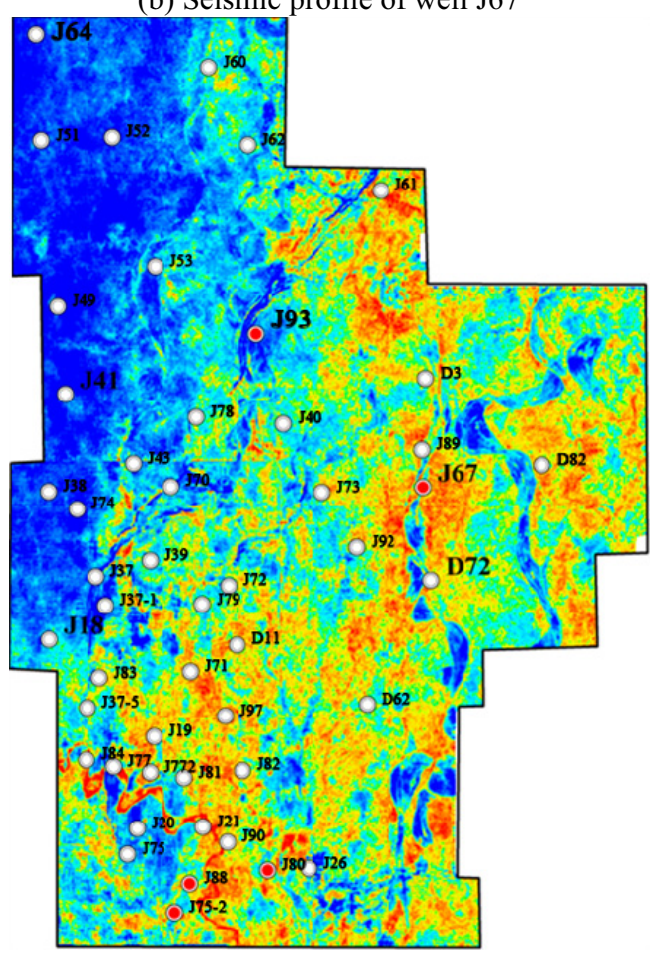

(c) Slice 2 amplitude attribute of S1 Formation

Figure 2. Stratal slicing at the top of S1 oil formation in Jiangqiao area, western slop 
Table 1. Prediction results of channel sand bodies in Saertu reservoir on western slope

\begin{tabular}{|c|c|c|c|c|}
\hline $\begin{array}{c}\text { Oil } \\
\text { formation }\end{array}$ & $\begin{array}{c}\text { Distribution } \\
\text { area/km }\end{array}$ & $\begin{array}{c}\text { Channel } \\
\text { width } / \mathrm{km}\end{array}$ & $\begin{array}{c}\text { Channel } \\
\text { direction }\end{array}$ & $\begin{array}{c}\text { Well } \\
\text { coincidence } \\
\text { rate/\% }\end{array}$ \\
\hline S0 & $133.7 \sim 202.8$ & $0.05 \sim 1.5$ & $\begin{array}{c}\text { Northeast } \\
\sim \text { Southwest }\end{array}$ & 84 \\
\hline S1 & $129.3 \sim 131.9$ & $0.08 \sim 1.6$ & $\begin{array}{c}\text { North } \\
\sim \text { South }\end{array}$ & 84 \\
\hline S23 & $232.5 \sim 287.5$ & $0.50 \sim 3.0$ & $\begin{array}{c}\text { Northwest } \\
\sim \text { Southeast }\end{array}$ & 78 \\
\hline
\end{tabular}

curve to establish the initial model, spatial variability structure instead of variation function analysis, unbiased optimal estimation on the high frequency components. The results of seismic inversion are not only constrained by seismic facies in space, but also accord with sedimentary law in plane, and finally the accuracy and reliability of reservoir prediction are improved effectively. Waveform indication inversion changes the traditional spatial geostatistics method based on variational function and adopts the "seismic wave-driven structured inversion" algorithm. The flow chart of the algorithm is as follows :(1) select a sample well by comparing the seismic waveform; (2) Statistical sample well curve structure; (3) Simulate the high frequency components of the initial model according to the selected samples and the determined structure, meet the conditional distribution probability calculated by the sample well statistics, and make the simulation results conform to the seismic intermediate frequency impedance and well curve structure characteristics. Finally, the simulation realizes the idea of "phasecontrolled inversion" and improves the certainty of highfrequency components.

Based on the prediction of sand body distribution by stratigraphic slicing, the seismic waveform indication inversion function in SMI software is used to quantitatively predict the fourth stage of the river in The S1 and S23 oil formation in the west slope. From the profile (Figure 3), two-stage channel sand bodies can be identified, and the thickness of four-stage channel sandstone can be predicted quantitatively by inversion finally (Figure 4). The absolute error of sandstone thickness prediction is $0 \sim 1.6 \mathrm{~m}$ with an average of $0.32 \mathrm{~m}$. The error meets the requirements of reservoir prediction.

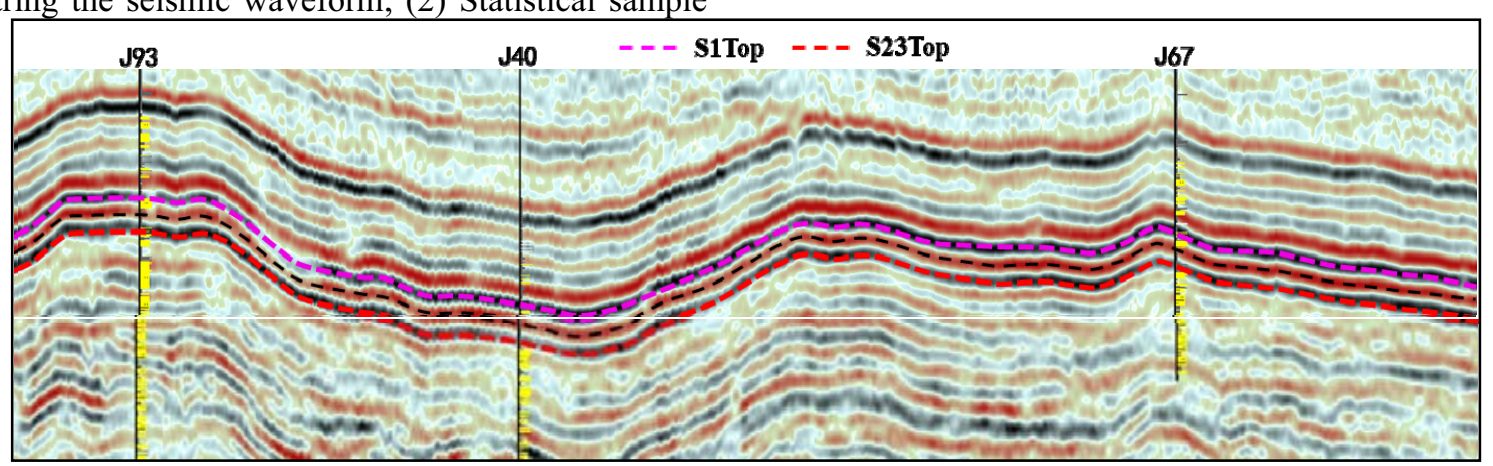

(a)Seismic Profile

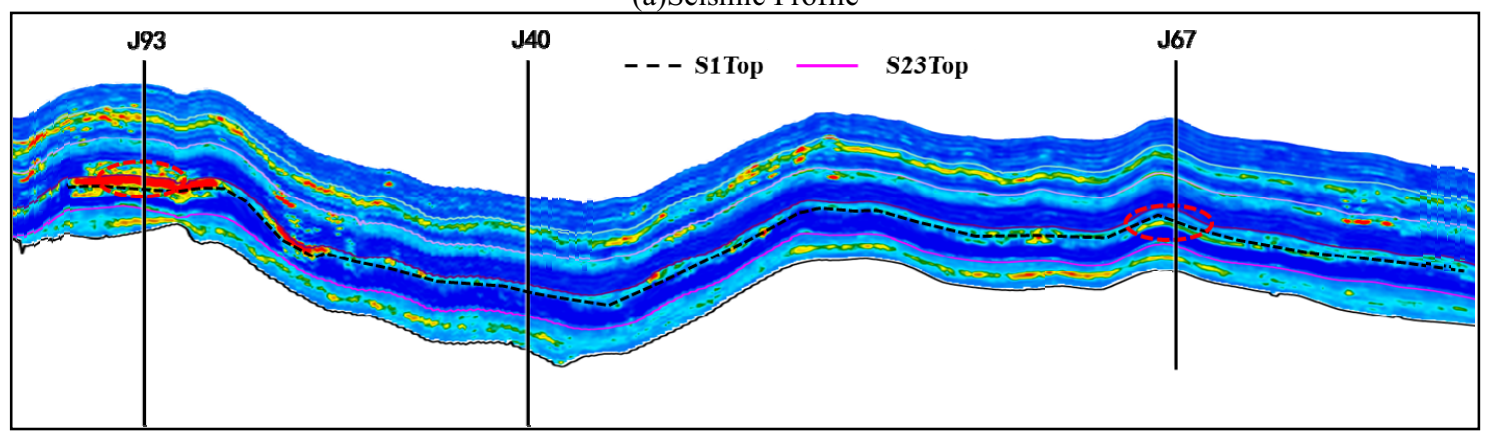

(b)Inversion Profile

Figure 3. Waveform Indicating Inversion of Connected Well Seismic Profile

\section{Conclusion}

(1) There are differences in the geophysical response characteristics in different areas of the S0 oil formation on the western slope, in northern and central regions channel sand cervix well response in low speed, low density characteristics and seismic response of weak amplitude,but the reflection characteristics of logging response of the channel sand body in southern area is high-speed, high-density characteristics, seismic response is a strong amplitude reflection characteristics. The geophysical response characteristics of S1 and S23 oil formation are basically the same. The logging response is characterized by low density and low velocity, while the seismic response is characterized by weak amplitude reflection.

(2) After 90 degree phase transformation, the seismic reflection axis is symmetric with respect to the sandstone layer, and the channel sand body has obvious characteristics, completely corresponding to the crest reflection. The two-stage channel is predicted by using the amplitude property in the S0 oil formation. By using the amplitude property of formation slice, two-stage 


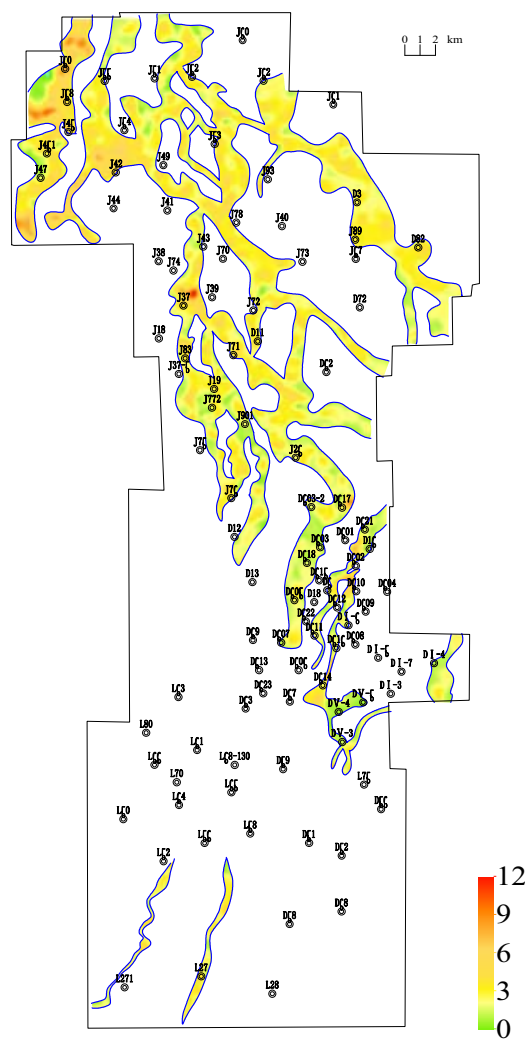

(a) Lower part of S23 reservoir

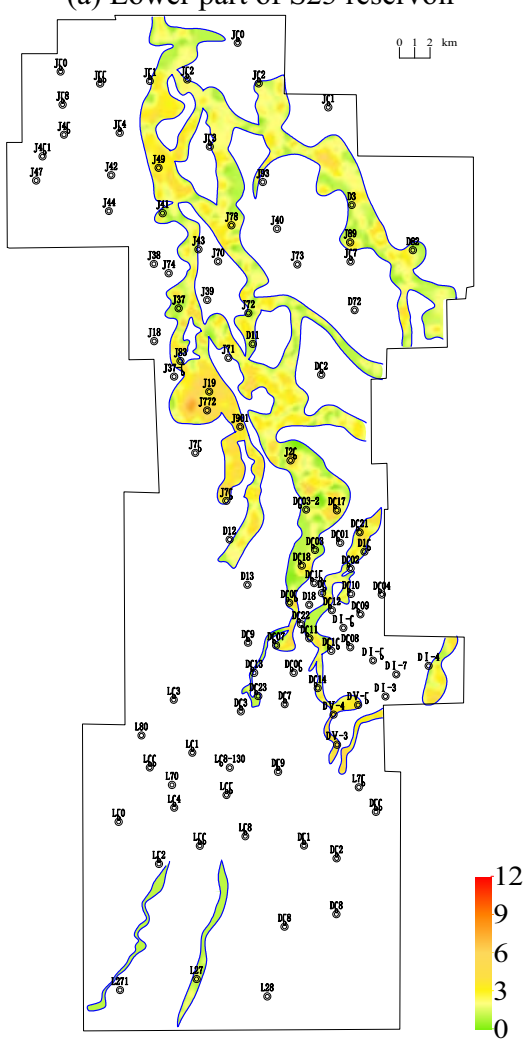

(b) Upper part of S23 reservoir

Figure 4. Prediction plan of channel sandstone thickness of S23 reservoir formation on western slope

channel can be predicted respectively in the $\mathrm{S} 1$ and S23 oil formations. Among them, the distribution area of the channel sand body of The S0 formation is $133.7 \sim 202.8 \mathrm{~km}^{2}$, the width of the channel is $0.05 \sim 1.5 \mathrm{~km}$, and the well coincidence rate is $84 \%$. The distribution area of channel sand body in $\mathrm{S} 1$ oil formation is $129.3 \sim 131.9 \mathrm{~km}^{2}$, the width of channel is $0.08 \sim 1.6 \mathrm{~km}$, and the well coincidence rate is $84 \%$. The distribution area of channel sand body of S23 oil formation is $232.5 \sim 287.5 \mathrm{~km}^{2}$, the width of channel is $0.50 \sim 3.0 \mathrm{~km}$, and the well coincidence rate is $78 \%$.

(3) Waveform indication inversion technique is used to quantitatively predict the channel sand body thickness in the fourth stage of the S1 and S23 oil formation. The absolute error of sandstone thickness prediction is $0 \sim 1.6 \mathrm{~m}$, with an average of $0.32 \mathrm{~m}$.

\section{Acknowledgments}

This work was financially supported by the National Science and Technology Major project "Key Technologies for Effective Use of Complex Reservoir Scale with Low permeability and Extra Low Permeability"(2017ZX05013006).

\section{References}

1. Lv Yanfang, WAN Jun, LIU Jiangtao, Et al. Journal of Jilin University:Earth Science Edition 38, 425 (2008)

2. Sun Jianguo, FU Guang, LIU Jiangtao. Petroleum Geology \& Oilfield Development in Daqing 25, 7 (2006)

3. Lin Chunhua, Xu Yanbin, Chen Junliang, et al. Journal of Yangtze University(Natural Science Edition) 12, 21(2015)

4. Yao Zhongwen, Liu Xingdong. Journal of Oil and Gas Technology 35, 73(2013)

5. Ji Xianwei. Unconventional Oil \& Gas 05, 23,(2019)

6. Zeng H L, Backus M M. Geophysics 70, C7(2005a)

7. Zeng H L, Backus M M. Geophysics 70, C17(2005b)

8. Zeng H L. Interpretation ,6, SD1(2018)

9. Sheriff R E. Encyclopedic Dictionary of Applied Geophysics(4thEdition).(SEG, 2002)

10. Zhu Xiaomin, Dong Yanlei, ZENG Hongliu, et al. Journal of Palaeogeography 21, 189(2019)

11. Zhu Xiaomin, Zeng Hongliu, Dong Yanlei, Principle of seismic sedmimentology and its application. (Petroleum Industry Press, Beijing, 2017)

12. Li Yongyi. Journal of Yangtze University(Natural Science Edition) 15, 9(2018)

13. Fan Xiaoyi, Yao Guangqing, Yang Zhenfeng, et al. Earth Science 43, 786(2018)

14. GUO Jingxing, WANG Xiaoting, LIU Wenkai, et al. Petroleum Geology \& Oilfield Development in Daqing 37, 125(2018)

15. Huang Wei, Wang Shibo, Zhang Yupeng, et al. Petroleum Geology \& Oilfield Development in Daqing 37, 1(2018) 
16. Cheng Shunguo,Jiang Yan,Sun Liyan. Petroleum Geology \& Oilfield Development in Daqing 32, 141(2013)

17. Gao Ruiqi,Cai Xiyuan, et al. Formation conditions and distribution of oil fields in Songliao Basin. (Petroleum Industry Press, Beijing, 1997)

18. Zhu Zhicheng, Wei Bize, Zhang Wangsheng, et al. Tectonic geology. (China University of Geosciences press, Wuhan, 1999)

19. Zhuo Hongchun, Lin Chunming, Feng Zhiqiang, et al. Acta Sedimentologica Sinica 25, 29(2007)

20. Jiang Hongliang, Zhang Mingxue, Huo Ling. Journal of Daging Petroleum Insititute 30, 14(2006)

21. Hu Xiaolan, Fan Tailiang, Zhang Xiaolong, et al. Journal of Jilin University(Earth Science Edition) 41, 647(2011)

22. Xu Deying, Liang Jiangping, Xin Renchen. Journal of Oil and Gas Technology 33, 11(2011)

23. Jiang Tao, Xin Renchen. Journal of Northeast Petroleum University 39, 32(2015)

24. Qiu Chunguang, Liu Yanli.Special Oil and Gas Reservoir 18, 36(2011)

25. Wang Liuhua. Science Technology and Engineering 12, 2153(2012)

26. Ji Xianwei. Study on sedimentary characteristics of Saertu reservoir in west clinoform region of northern Songliao basin. (Daqing Petroleum Institute,2007)

27. Li Ruyi. West-China Exploration Engineering 3, 38(2016)

28. Ke Qin. (2018) Channel sand body prediction based on seismic attributes- A case study of J93 well in the western slope area of Songliao basin. In : CPS/SEG International Geophysical Conference. Beijing. 776

29. Zhu Xiaomin, Zeng Hongliu, Dong Yanlei, et al.Translater. Zeng Hongliu, et al.Writer. Collected Works of Seismic sedimentology. (Petroleum Industry Press, Beijing, 2011)

30. Dong Chunmei, Zhang Xianguo, Lin Chengyan. Acta Sedmentologica Sinica 24, 698(2006)

31. Zeng Hong liu ,Backus M M , Barrow K T and Tyler N. Geophysics 63, 502(1998)

32. Zeng Hongliu, Henry S C, Rio la J P. Geophysics 63, 514 (1998)

33. Wu Shenghe. Reservoir Characterization Modeling. (Petroleum Industry Press, Beijing, 2010)

34. Yang Wei. Petroleum Geology \& Oilfield Development in Daqing 37,137(2018)

35. Wang Hai. Complex Hydrocarbon Reservoirs 13,33(2020) 